ACM exposure and ARD were estimated using Poisson regression.

Results Overall 26,401(79\%) AWR registrants were linked to health data; $97 \%$ were male. The mean age at cohort entry was 36 years. The most common industries represented were construction (61\%), manufacturing (20\%) and education (10\%). Among men and women rates were markedly increased for mesothelioma [M:SIR 6.55(95\% CI=5.34-7.96); W:SIR 19.3 (3.87-56.3)] and pulmonary fibrosis [M:SIR 13.8(11.9-15.9); W:SIR 9.15(2.46-23.4)]. The risk of asbestosis was also elevated, but did not reach statistical significance among women [M:SIR 11.1(9.46-12.9); W:SIR 1.21(0.02-6.75)]. Among men and women, rates of COPD and lung cancer were elevated, but few cases were observed among women. Compared to workers with 238 hours had increased rates of lung cancer [RR 1.3(1.07-1.57)], mesothelioma [RR 3.13(1.945.06)], asbestosis [RR 3.31(2.33-4.71)], COPD [RR 1.34 (1.22-1.48)], and pulmonary fibrosis [RR 1.86(1.34-2.58)].

Conclusion Exposure to asbestos in construction and building maintenance continues to contribute to ARD incidence. Though a Canadian ban on asbestos use in new products is encouraging, it is likely to have minimal impact on ARD resulting from construction activities, where exposure to existing ACM will persist.

\section{RF-274 CARDIORESPIRATORY FITNESS OF POLICE RECRUITS: NORM-REFERENCED VALUES AND 14-YEAR TEMPORAL TREND.}

'Sébastien Poirier, Julie Houle, François Trudeau. 'Université du Québec à Trois-Rivières, Canada

\subsection{6/OEM-2021-EPI.382}

Introduction Many have highlighted the increased risk of cardiovascular diseases (CVD) among police officers. Because a low cardiorespiratory fitness (CRF) in young adulthood is associated with a higher risk of CVD incidence, the identification of police officers exhibiting low CRF upon entry in the profession could allow the implementation of targeted strategies for the primary prevention of CVD. Unfortunately, reference values for the CRF of Canadian police recruits are not yet available.

Objectives This research aimed to provide reference standards for the CRF of police recruits in Québec (Canada) and to evaluate the trend in the CRF of recruits over a 14-year period.

Methods This cross-sectional study was divided into two research phases. First, fifty-one police cadets performed both an indirect calorimetry assessment of their maximal oxygen consumption (VO2max) and the Physical Abilities Test (PAT) used for the recruitment of police officers in the province of Québec. Using results from both tests, a model was developed to estimate $\mathrm{VO}_{2}$ max based on PAT results. The CRF of police recruits who completed the PAT from 2004 to 2017 was then retrospectively assessed using the previously developed model. Results Based on the analysis of 7234 PAT results, the average $\dot{\mathrm{V}} \mathrm{O}_{2} \max$ was $53.33 \pm 2.90 \mathrm{ml} \cdot \mathrm{kg}^{-1} \cdot \mathrm{min}^{-1}$ for male recruits and $43.78 \pm 2.89 \mathrm{ml} \cdot \mathrm{kg}^{-1} \cdot \mathrm{min}^{-1}$ for female recruits. Furthermore, bivariate correlation analyses suggested small but significant increases in the $\dot{\mathrm{VO}_{2}}$ max of both male $\left(\mathrm{r}_{\mathrm{s}}=.105, \mathrm{p}<\right.$ $.001)$ and female recruits $\left(r_{s}=.125, p<.001\right)$ over the 14 year period studied.
Conclusion Our results suggest that the CRF of police recruits in Québec is considerably higher than their North American peers. Furthermore, although clear conclusions cannot be drawn from our temporal trend analyses, our data suggest that the CRF of police officers from this population did not decline over the last decades as previously suggested by others.

\section{RF-408 WORK-RELATED RESPIRATORY SYMPTOMS AND ECZEMA AMONG SWEDISH EYELASH STYLISTS}

${ }^{1}$ Sara Gunnare, Helen Wahlkvist. ' Karolinska Institutet, Sweden

\subsection{6/OEM-2021-EPI.383}

Introduction Eyelash extension is a beauty treatment established in recent years. The eyelash stylists apply eyelash extensions on natural lashes, using adhesives based on cyanoacrylates. Exposure to cyanoacrylates may cause asthma and eczema.

Objectives The main objective was to survey work-related respiratory symptoms and eczema among eyelash stylists in Sweden. Occupational exposure and use of personal protective equipment were also studied.

Methods Questionnaires with focus on work-related respiratory symptoms, eczema and occupational exposure conditions were sent to 656 eyelash stylists in the four largest cities of Sweden (Stockholm, Göteborg, Malmö and Uppsala). The participants were identified by an internet reservation site for eyelash extensions and by social media. The participation rate was 26\% (169 respondents).

Results The main part of the respondents (74\%) had been working as eyelash stylists for more than 2 years. 59\% of them reported that they had respiratory symptoms and $15 \%$ that they had eczema (12-month prevalence). One third of the respondents had a colleague who had changed occupations due to respiratory symptoms or eczema. Almost 20\% reported that they had customers who had had respiratory symptoms in association with lash extension and almost $10 \%$ stated that customers got eczema. Approximately $85 \%$ of the respondents reported that they used personal protective equipment, but more than $50 \%$ only used surgical masks that do not protect against acrylates. About 20\% reported that they were using protective gloves at work.

Conclusion The survey shows that many eyelash stylists have respiratory symptoms and that some of them have eczema. The surgical masks most commonly used do not provide sufficient protection against acrylates present in the work environment of the eyelash stylists. In addition, the survey indicates that far too few eyelash stylists use protective gloves at work.

\section{RF-417 OCCUPATIONAL RHINITIS AND ASTHMA CAUSED BY ISOCYANATES}

${ }^{1}$ Siwar Chemingui, Jihen Hsinet, Saloua Ismail, Amani Dallagi, Nihel Khouja, Ines Aissa, Aida Benzarti, Abdelmajid Ben Jemaa. 'Hôpital La Rabta, Tunisia

\subsection{6/OEM-2021-EPI.384}

Introduction Isocyanates are strong respiratory sensitizers. Repeated and prolonged occupational exposure to these 